\title{
Acute aortic valve prolapse in Marfan's syndrome
}

\author{
N.J. Carr and S.A. Cullen
}

RAF Institute of Pathology and Tropical Medicine, Halton, Aylesbury, Bucks HP22 5PG, UK

\begin{abstract}
Summary: A 22 year old man with Marfan's syndrome died suddenly following acute aortic valve prolapse. Although aortic root involvement in Marfan's syndrome is common, we have found no previous description of this particular complication in the literature.
\end{abstract}

\section{Introduction}

Life expectancy is reduced in Marfan's syndrome, and it is the cardiovascular manifestations of the disease that lead to the poor prognosis. ${ }^{1,2}$ We report a case of Marfan's syndrome which is unusual in that degeneration of the aortic root resulted in a sudden fatal prolapse of the aortic valve.

\section{Case report}

A 22 year old baker was admitted to hospital with an influenza-like illness. For two days it was associated with several episodes of central chest pain which he described as a tightness in the chest 'as though someone was sitting on it'. Each episode lasted about half an hour. These were his only symptoms of cardiovascular disease and before this admission his health had been good and he had never complained of breathlessness, anginal pain or palpitations. Although Marfan's syndrome had not been diagnosed in his family, his father and brother measured $193 \mathrm{~cm}$ and $188 \mathrm{~cm}$ in height respectively, and his mother and sister were both $178 \mathrm{~cm}$ tall.

His appearance was typical of Marfan's syndrome. He was $198 \mathrm{~cm}$ tall, weighed $75 \mathrm{~kg}$ and had an arm span of $203 \mathrm{~cm}$. Examination revealed a pigeon chest, high arch palate and arachnodactyly. His pulse rate was 100 , collapsing, with a blood pressure of $130 / 55 \mathrm{mmHg}$. The apex beat was in the sixth intercostal space in the anterior axillary line where a systolic thrill was palpable. A pansystolic murmur was present at the apex and a long early diastolic murmur together with a fourth heart sound were heard at the right sternal border.

Correspondence: Squadron Leader N.J. Carr, M.B., B.S. Accepted: 20 September 1990
Ophthalmic examination disclosed a persistent hyaloid artery and deep anterior chambers but there was no ectopia lentis.

Laboratory investigations were unremarkable. Radiography demonstrated an enlarged heart with a widely dilated aortic root. Echocardiography showed a volume overloaded left ventricle with mild left ventricular hypertrophy; the end diastolic dimension was $6.8 \mathrm{~cm}$ and the end systolic dimension $5.5 \mathrm{~cm}$. The aortic root was greatly enlarged at $7 \mathrm{~cm}$. Cardiac catheterization, performed 10 day after his episodes of chest pain, was reported as showing severe aortic regurgitation and mild mitra regurgitation but no evidence of arch dissection. The mean pulmonary wedge pressure was $18 \mathrm{mmHg}$, the left ventricular pressure $100 /$ $2 \mathrm{mmHg}$ and the aortic pressures $100 / 45 \mathrm{mmHg}$. The findings suggested aortic regurgitation due to dilatation of the aortic ring and the patient was referred for excision and replacement of the ascending aorta and possible resuspension of the aortic valve. However, one month later, before the operation could be performed, he complained of more severe chest pain, suddenly collapsed and died.

Post-mortem examination showed a greatly enlarged heart weighing $940 \mathrm{~g}$ with dilatation and hypertrophy of both ventricles. The mitral, tricuspid and pulmonary valves all showed a moderate degree of dilatation of their rings (mitral circumference $145 \mathrm{~mm}$, tricuspid $148 \mathrm{~mm}$, pulmonary $115 \mathrm{~mm})$. However, their cusps appeared normal and there was no evidence of a 'floppy' mitral valve.

The aortic ring was dilated, measuring $130 \mathrm{~mm}$ in circumference, and its valve was grossly incompetent. A jet lesion was seen on the interventricular septum. Immediately above the posterior commissure there was a V-shaped intimal tear $28 \mathrm{~mm}$ long (Figure 1). This had passed behind the posterior commissure resulting in detachment of the commissure from the aortic wall and marked prolapse of the right coronary cusp and non-coronary cusp. Histological examination of the aorta in the 


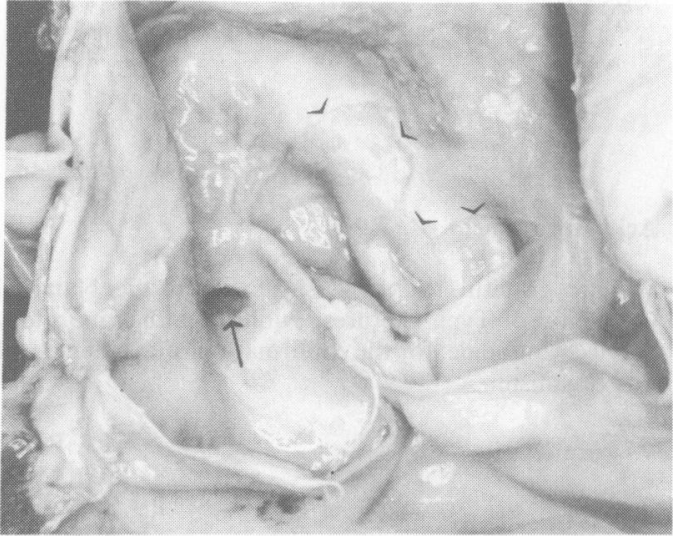

Figure 1 The ascending aorta, aortic valve and origin of the right coronary artery (arrow). A V-shaped tear causing loss of commissural support is visible (arrowheads).

vicinity of the tear showed the appearances of cystic medial necrosis.

Fusiform dilatation of the ascending aorta extended to the origin of the brachiocephalic artery. This aneurysmal dilatation involved the sinuses of Valsalva resulting in an apparently high origin of the right coronary artery. In addition, the aorta showed several old intimal tears. The coronary arteries showed no atheroma. The lungs were moderately oedematous.

It was considered that death was due to sudden prolapse of the aortic valve, which, in addition to severe haemodynamic effects, could have caused acute myocardial ischaemia due to failure of coronary artery perfusion.

\section{References}

1. Murdoch, J.L., Walker, B.A., Halpern, B.L., Kuzma, J.W. \& McKusick, V.A. Life expectancy and causes of death in the Marfan syndrome. N Engl J Med 1972, 286: 804-808.

2. McKusick, V.A. The cardiovascular aspects of Marfan's syndrome: a heritable disorder of connective tissue. Circulation 1955, 11: $321-342$.

3. Carter, J.B., Sethi, S., Lee, G.B. \& Edwards, J.E. Prolapse of semilunar cusps as causes of aortic insufficiency. Circulation 1971, 43: 922-931.

4. Frieden, J., Hurwitt, E.S. \& Leader, E. Ruptured aortic cusp associated with an heritable disorder of connective tissue. Am J Med 1962, 33: 615-618.

\section{Discussion}

Lesions of the aorta and its valve are common in Marfan's syndrome; $;^{2-4}$ in one series of 34 postmortem cases ${ }^{5}$ only one had an entirely normal heart. Dilatation of the aortic ring, dilatation of the ascending aorta and aortic incompetence all occur singly or in combination. Weakening of the aortic wall may also result in dissecting aneurysm, perforation, or limited intramedial dissection forming a laceration or tear with retraction of the edges. This weakening is often associated with the histological changes of cystic medial necrosis, ${ }^{2,4}$ as in this case. The chordae tendinae may be elongated and thinned, and they occasionally rupture. Other cardiovascular abnormalities reported frequently in Marfan's syndrome include septal defects, patent ductus arteriosus, coarctation of the aorta and conduction defects. Common causes of death include congestive cardiac failure and rupture of dissecting aneurysm.

This case is unusual in that medial degeneration caused sudden prolapse of the aortic valve owing to loss of commissural support without associated dissection of the aorta.

There is clinical relevance in the recognition of cardiovascular involvement in Marfan's syndrome because surgical repair of most lesions is possible. ${ }^{6}$ Echocardiography is valuable in detecting and classifying lesions. ${ }^{7}$ In this case it is unfortunate that the patient died while he was on the waiting list for surgery.

\section{Acknowledgements}

We thank the Director General of Medical Services, Royal Air Force, for permission to publish this paper.

5. Goyette, E.M. \& Palmer, P.W. Cardiovascular lesions in arachnodactyly. Circulation 1953, 7: 373-379.

6. Nasrallah, A.T., Cooley, D.A., Goussous, Y., Hallman, G., Lufschanowski, R. \& Leachman, R.D. Surgical experience in patients with Marfan's syndrome, ascending aortic aneurysm and aortic regurgitation. Am J Cardiol 1975, 36: 338-341.

7. Pan, C.W., Chen, C.C., Wang, S.P., Hsu, T.L. \& Chiang, B.N. Echocardiographic study of cardiac abnormalities in families of patients with Marfan's syndrome. J Am Coll Cardiol 1985, 5: 1016-1020. 